\title{
Effect of electrode density on cycle performance and irreversible capacity loss for natural graphite anode in lithium ion batteries
}

\author{
Joongpyo Shim and Kathryn A. Striebel* \\ Environmental Energy Technologies Division, Lawrence Berkeley National Laboratory \\ Berkeley, CA 94720
}

\begin{abstract}
The effect of electrode thickness and density for unpressed and pressed natural graphite electrodes were studied using electrochemical characterization. Pressing the graphite electrode decreases the reversible capacity and the irreversible capacity loss during formation. As electrode density increased, the capacity retention at high rate increased until $0.9 \mathrm{~g} / \mathrm{cm}^{3}$, and then decreased. The cycle performances of the pressed graphite electrodes were more stable than the unpressed one. Pressing graphite electrode affected on its electrochemical characterization such as irreversible capacity loss, high rate cycling and cycle performance.
\end{abstract}

Keywords; Lithium-ion battery, natural graphite, anode

*Corresponding author; kastriebel@lbl.gov (K.A.Striebel) 


\section{Introduction}

Synthetic graphites, such as mesocarbon-microbead (MCMB) have been used commercially by many battery companies as anode materials in lithium-ion batteries because they have shown a reversible electrochemical behavior and a low, flat potential curve for the lithium intercalation/deintercalation process [1,2]. However, for all-electric and hybrid-electric vehicles, the lower-cost natural graphites are of more interest. Many approaches have been investigated for the stabilization of natural graphites to the point where the coulombic efficiencies approach that of the synthetics [3]. The dependence of the electrode preparation is critical to the performance of these materials. Recent reports on the relationships between the lithium intercalation process and pressure used during electrode preparation suggest that unpressed anodes yield superior performance due to faster kinetics and less disruption of the graphite morphology [4]. The dependence of SEI formation on anode density is far from solved. Some report a lower irreversible capacity loss (ICL) for more dense electrodes due to less exposed surface area [5]. For higher energy cells, it is clear from the patent literature and hearsay that pressing is a critical step in the production of high-performance anodes. In our search for a good anode for our low cost baseline EV cell technology, several different natural graphite materials were prepared and studied at different anode densities. We are investigating the dependence of the firstcycle irreversible capacity loss and cycling performance for different natural graphites on electrode loading and porosity.

Many factors influence the performance of graphite anodes. Type of graphite, including particle size, surface area, surface composition, and fraction of edge sites have all been shown to affect the charge of Li required to passivate the surface. Since this quantity of lithium directly affects the capacity of the cell, we are very interested in it. In addition, these factors can affect the stability of the anode layer. This translates to cell cyclability. Other electrode parameters such as layer porosity (or density) and binder content have also been studied. We have seen few reports dealing directly with the thickness (or capacity) of 
the anode layer. The dependence of anode density on the solid electrolyte interface (SEI) formation and cyclability is the subject of this work.

\section{Experimental}

The active materials used in this study are natural graphite (SL20, Superior Graphite Co.), 6\% carbon-coated natural graphite (GDR6, Mitsui Mining Co.) and synthetic graphite (MAG-10, Hitachi Chemical). The anodes consisted of graphite (90-92\%), PVdF binder (8-10\%) and $\mathrm{Cu}$ foil current collector (thickness $25 \mu \mathrm{m})$. Slurries for electrode casting were prepared from a mixture of the graphite and PVdF dissolved in 1-methyl-2pyrrolidinone (NMP). They were spread onto a $\mathrm{Cu}$ foil with different thickness and dried under vacuum at $120^{\circ} \mathrm{C}$ for $12 \mathrm{~h}$. After drying, the electrodes were compressed by bench top or roll press. All cells were assembled for testing in an Ar-filled glovebox.

Anodes were tested in two configurations: $30-\mathrm{mAh}\left(12-\mathrm{cm}^{2}\right)$ pouch lithium-ion cells prepared at LBNL from pressed and unpressed electrodes with $1 \mathrm{M} \mathrm{LiPF}_{6} / \mathrm{EC} / \mathrm{DEC}$ electrolyte and $\mathrm{LiCoO}_{2}$ electrode. These pouch cells were cycled between 2.7 and 4.2 volts

with a taper charge at $4.2 \mathrm{~V}$ to a low-current cut-off of $\mathrm{C} / 20.1-\mathrm{cm}^{2}$ electrodes were assembled into metal Swagelok cells with Celgard separator, electrolyte (1M $\mathrm{LiPF}_{6} / \mathrm{EC} / \mathrm{DEC}$ ) and $\mathrm{Li}$ foil reference/counter electrodes. Formation was carried out with two $\mathrm{C} / 25$ cycles and cycling was carried out with the same voltage limits at $\mathrm{C} / 2$. The voltage limits of 0.01 to 1.0 were used with a taper charge at $0.01 \mathrm{~V}$ (vs. $\mathrm{Li} / \mathrm{Li}^{+}$).

\section{Results and Discussion}

\section{Formation}

Fig. 1 shows the first and second cycles for natural graphite (SL20), synthetic graphite (MAG-10) and 6\% carbon-coated natural graphite (GDR6) at C/25. Table 1 shows the 
reversible and irreversible capacities of these graphites for the formation cycle. SL20 and MAG-10 shows lower irreversible capacity loss (ICL) than GDR6 because the amorphous carbon black on the surface of GDR6 may induce the side reaction with the electrolyte. The reversible capacity of this SL20 natural graphite is very close to theoretical capacity.

Fig. 2 shows the variation of electrode thickness and density for SL20 natural graphite on pressure with loading of $5.0 \mathrm{mg} / \mathrm{cm}^{2}$. The electrode thickness decreased by pressing. The thickness reached to $50 \%$ of unpressed electrode around $300 \mathrm{~kg} / \mathrm{cm}^{2}$ and its density was $1.38 \mathrm{~g} / \mathrm{cm}^{3}$.

Fig. 3 shows the charge and discharge capacities of natural graphite anodes with different

density for first and second cycles. The charge and discharge capacities decreased slightly with an increase of electrode density. The first charge capacities for all samples were over $400 \mathrm{mAh} / \mathrm{g}$ and reversible capacities at second cycle were around $360 \mathrm{mAh} / \mathrm{g}$. Fig. 4 shows the total irreversible capacity loss (ICL) for first and second cycles. ICL decreased slightly with an increase of electrode density. ICL for all electrode density was $60-100 \mathrm{mAh} / \mathrm{g}$ and $8-12 \%$. It has been reported that ICL comes from the side reaction between electrolyte and surface of graphite [6,7]. Zaghib and co-workers reported that the surface area of natural graphite was directly related to ICL regardless of particle size [8] but the reversible capacity was affected by the particle size of natural graphite [9]. If the electrode was compressed or rolled, the porosity and active surface area of electrode would be decreased. Also, the electrolyte volume in electrode and the contact area between electrolyte and graphite would be decreased. The result from Fig. 4 can be explained by those reasons.

\section{High rate utilization}

Fig. 5 shows the voltage profiles for SL20 natural graphite with $0.9 \mathrm{~g} / \mathrm{cm}^{3}$ of electrode density at various $\mathrm{C}$ rates. Fig. 6 shows the variation of high rate capacity on electrode density at $3 \mathrm{C}$. The graphite electrode around $0.9 \mathrm{~g} / \mathrm{cm}^{3}$ shows more than $90 \%$ of capacity retention at $3 \mathrm{C}$ rate. However, high rate capacity for the graphite electrode pressed to greater than $1.0 \mathrm{~g} / \mathrm{cm}^{3}$ decreased. Highly pressed graphite electrode showed lower capacity 
retention than unpressed electrode. Aurbach and co-workers also reported that pressed graphite electrodes showed lower reversible capacity than unpressed ones [4]. They proposed that compressing graphite electrode might cause block the diffusion of lithium ion into the active mass or damage them. But, their graphite electrode was subjected to higher pressures (a few ton per $\mathrm{cm}^{2}$ ) than ours (in Fig. 2). Pressing of the natural graphite anodes increased electronic conductivity of the solid phase [10]. However, there will be a trade-off between decreasing ohmic resistance and ICL on the one hand and increasing polarization resistance of $\mathrm{Li}^{+}$transport in the electrolyte through electrode on the other, as porosity and thickness decrease. That will lead to a maximum. The role electric conductivity in the performance of this electrode is the subject of future work.

\section{Cyclability}

Fig. 7 shows the discharge capacity during $\mathrm{C} / 2$ cycling for unpressed and pressed graphite electrodes in half-cell and pouch cell. Although the pouch cell with unpressed synthetic graphite (density $0.51 \mathrm{~g} / \mathrm{cm}^{3}$ ) and $\mathrm{LiCoO}_{2}$ electrodes showed rapid capacity fading, the capacity retention of that with pressed electrodes $\left(1.11 \mathrm{~g} / \mathrm{cm}^{3}\right.$ for anode) is very flat. We don't discuss the effect of pressing for cathode in this work. However, Aurbach and co-workers have already reported the advantage for compressing cathode [4]. In halfcell test, the pressed natural graphite electrode $\left(0.9 \mathrm{~g} / \mathrm{cm}^{3}\right)$ showed better capacity retention than the unpressed one $\left(0.76 \mathrm{~g} / \mathrm{cm}^{3}\right)$.

When the composite electrode including active particle and binder is pressed, the porosity and thickness of electrode decrease and the stress for particles increases. If the porosity of electrode would be estimated by true density of graphite $(2.26 \mathrm{~g} / \mathrm{cc})$ and PVdF $(1.78 \mathrm{~g} / \mathrm{cc})$, it decreased from $65 \%$ to $40 \%$ before and after pressing. Active surface area in electrode decreases with a decrease of porosity. Although the electrode porosity by pressing decreased $60 \%$, the capacity decreased $7-8 \%$ only in Fig. $3.40 \%$ of porosity is quite enough to allow electrolyte penetration into electrode. These results are consistent with the data of Novak et al $[11,12]$. Manev et al. reported that there was optimum porosity 
for the performance of graphite electrode [13]. We also observed the optimum compacting pressure for high rate capacity and constant cycling, although it was lower than their data because of different pressing technique. Cycle performance and irreversible capacity loss are strongly affected by pressing electrode and these results are able to apply to battery production commercially.

\section{Conclusion}

The performance of natural graphite anodes on electrode density and porosity was investigated in $1 \mathrm{M} \mathrm{LiPF}_{6} / \mathrm{EC} / \mathrm{DEC}$. The capacities of natural graphite electrodes for the first and second cycles decreased with an increase of electrode density by pressing. Also, pressed electrodes showed lower irreversible capacity loss than unpressed electrodes. The high rate utilization and cyclability of graphite electrode at moderate density of $0.9 \mathrm{~g} / \mathrm{cm}^{3}$ showed better performance than bother unpressed $\left(0.76 \mathrm{~g} / \mathrm{cm}^{3}\right)$ and highly pressed $\left(1.38 \mathrm{~g} / \mathrm{cm}^{3}\right)$ electrodes. This result may be due to a trade-off between ohmic and polarization resistances in the porous electrode.

\section{Acknowledgement}

We acknowledge the supply of natural graphite from Superior Graphite Company. This research was funded by the Assistant Secretary for Energy Efficiency and Renewable Energy, Office of Advanced Automotive Technologies, U. S. Department of Energy, under contract number DE- AC03-76SF00098.

\section{References}

1. T. Nagaura, Prog. In Batteries \& Battery Mat., 10, (1991) 218

2. T. Ohzuku, Y. Iwakoshi, and K. Sawai, J. Electrochem. Soc., 140 (1993) 2490 
3. H. Wang, and M. Yoshio, J. Power Sources, 101 (2001) 35

4. J.S Gnanraj, Y.S. Cohen, M.D. Levi, and D. Aurbach, J. Electroanal. Chem., 516 (2001) 89

5. K. Guerin, A. Fevrier-Bouvier, S. Flandrois, B. Simon, and P. Biensan, Electrochim. Acta, 45 (2000) 1607

6. D. Aurbach, A. Zaban, Y. Ein-Eli, I. Weissman, O. Chusid, B. Markovsky, M. Levi, E. Levi, A. Schechter, and E. Granot, J. Electrochem. Soc., 68 (1997) 91

7. D. Aurbach, B. Markovsky, I. Weissman, E. Levi, and Y. Ein-Eli, Electrochim. Acta, 45 (1999) 67

8. K. Zaghib, G. Nadeau and K. Kinoshita, J. Electrochem. Soc., 147 (2000) 2110

9. K. Zaghib, F. Brochu, A. Guerfi and K. Kinoshita, J. Power Sources, 103 (2001) 140

10. A.M. Sastry, BATT program quarterly report, April 2002, Lawrence Berkeley National Laboratory

11. P. Novak, W. Scheifele, M. Winter, and O. Haas, J. Power Sources, 68 (1997) 267

12. V. Manev, I. Naidenov, B. Puresheva, and G. Pistoia, J. Power Sources, 57 (1995) 133

13. V. Manev, I. Naidenov, B. Puresheva, P. Zlatilova, and G. Pistoia, J. Power Sources, 55 (1995) 211 


\section{List of figures}

Fig. 1. First and second cycles of natural and synthetic graphites at $C / 25$ : (a) Natural graphite (SL20); (b) synthetic graphite (MAG-10); (c) 6\% carbon-coated natural graphite (GDR6).

Fig. 2. Variation of electrode thickness and density for SL20 natural graphite by pressing: Pressing time $5 \mathrm{sec}$.

Fig. 3. Charge (filled symbols) and discharge (open symbols) capacities of unpressed and pressed graphite electrodes for first (a) and second (b) cycles.

Fig. 4. Total irreversible capacity loss (ICL) of natural graphite electrode for first and second cycles.

Fig. 5. Voltage profiles for SL20 natural graphite with $0.9 \mathrm{~g} / \mathrm{cm}^{3}$ of electrode density at various $\mathrm{C}$ rates: Charge rate $\mathrm{C} / 2$.

Fig. 6. Variation of high rate capacity on electrode density at 3C.

Fig. 7. Capacity retention for electrodes and cells with pressed (open symbols) and unpressed (filled symbols) electrodes: $\triangle \boldsymbol{\Delta}$ pouch cell, $\square \square$ natural graphite electrode. 
Table 1. Reversible and irreversible capacities of natural and synthetic graphite for first and second cycles.

\begin{tabular}{lccc}
\hline Graphite & Q $_{\text {rev }}(\mathrm{mAh} / \mathrm{g})$ & ICL $(\%)$ & ICL $(\mathrm{mAh} / \mathrm{g})$ \\
\hline SL20 & 370 & 9.2 & 75 \\
MAG-10 & 328 & 8.6 & 62 \\
GDR6 & 340 & 13.3 & 108 \\
\hline
\end{tabular}



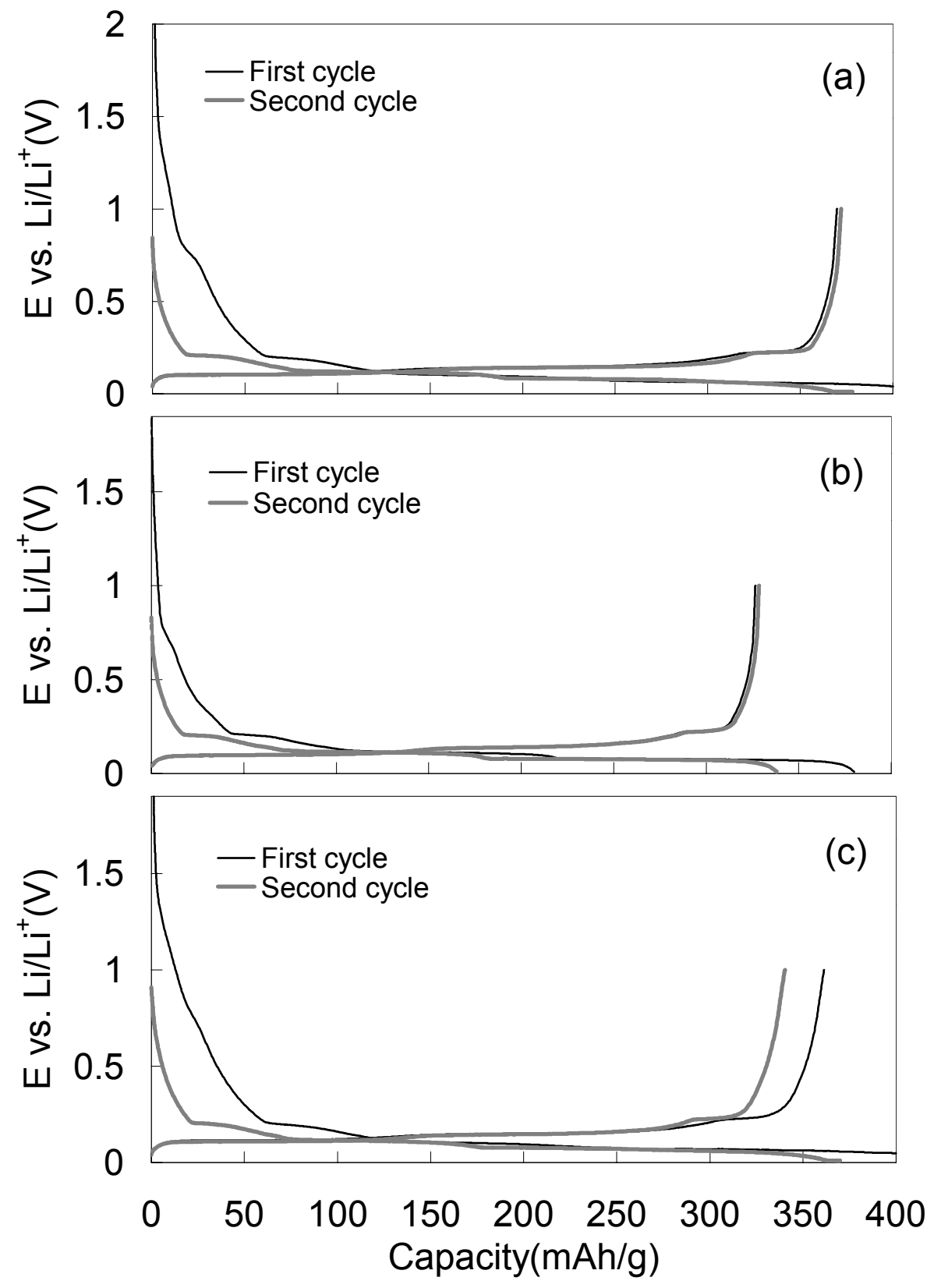

Fig. 1 


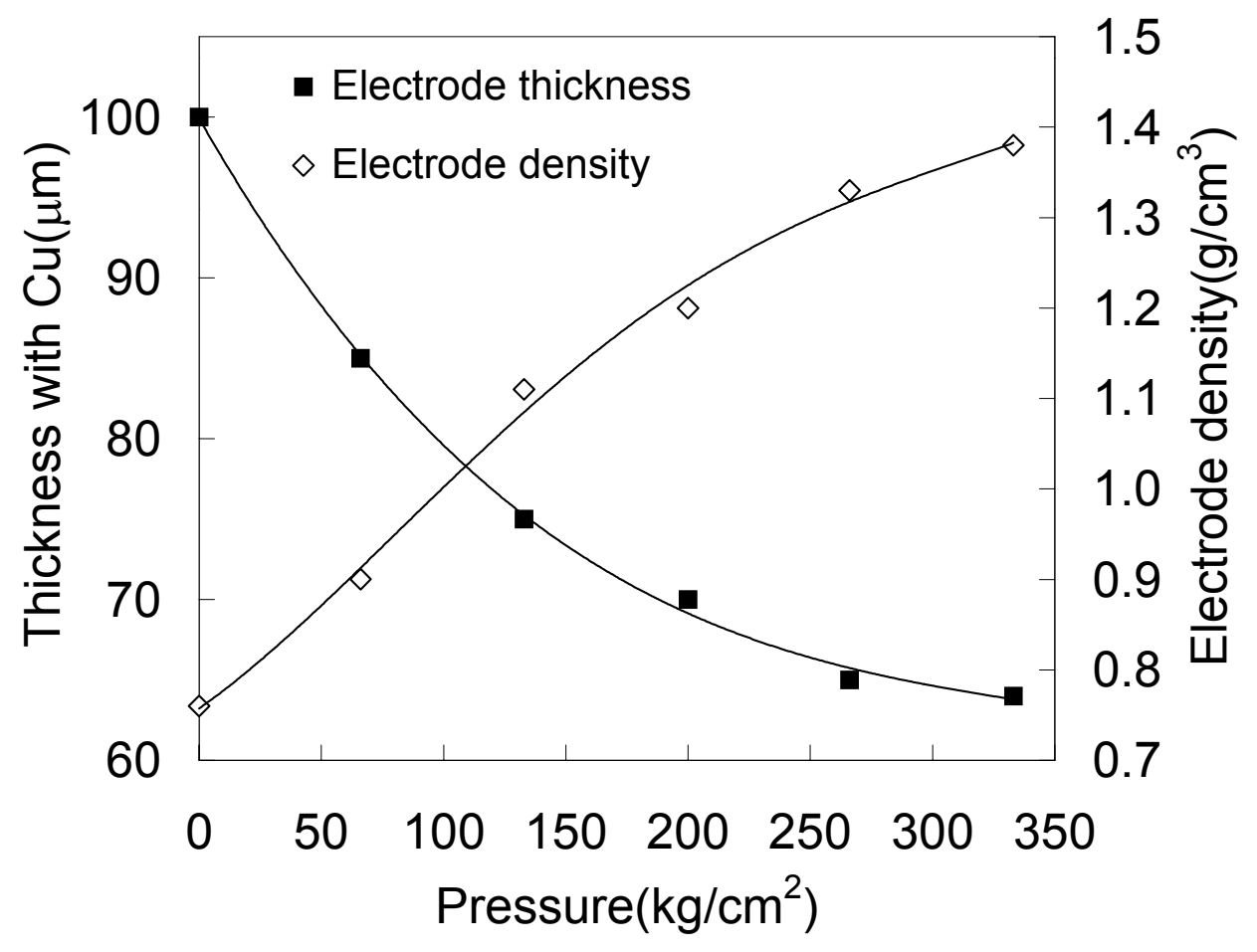

Fig. 2. 

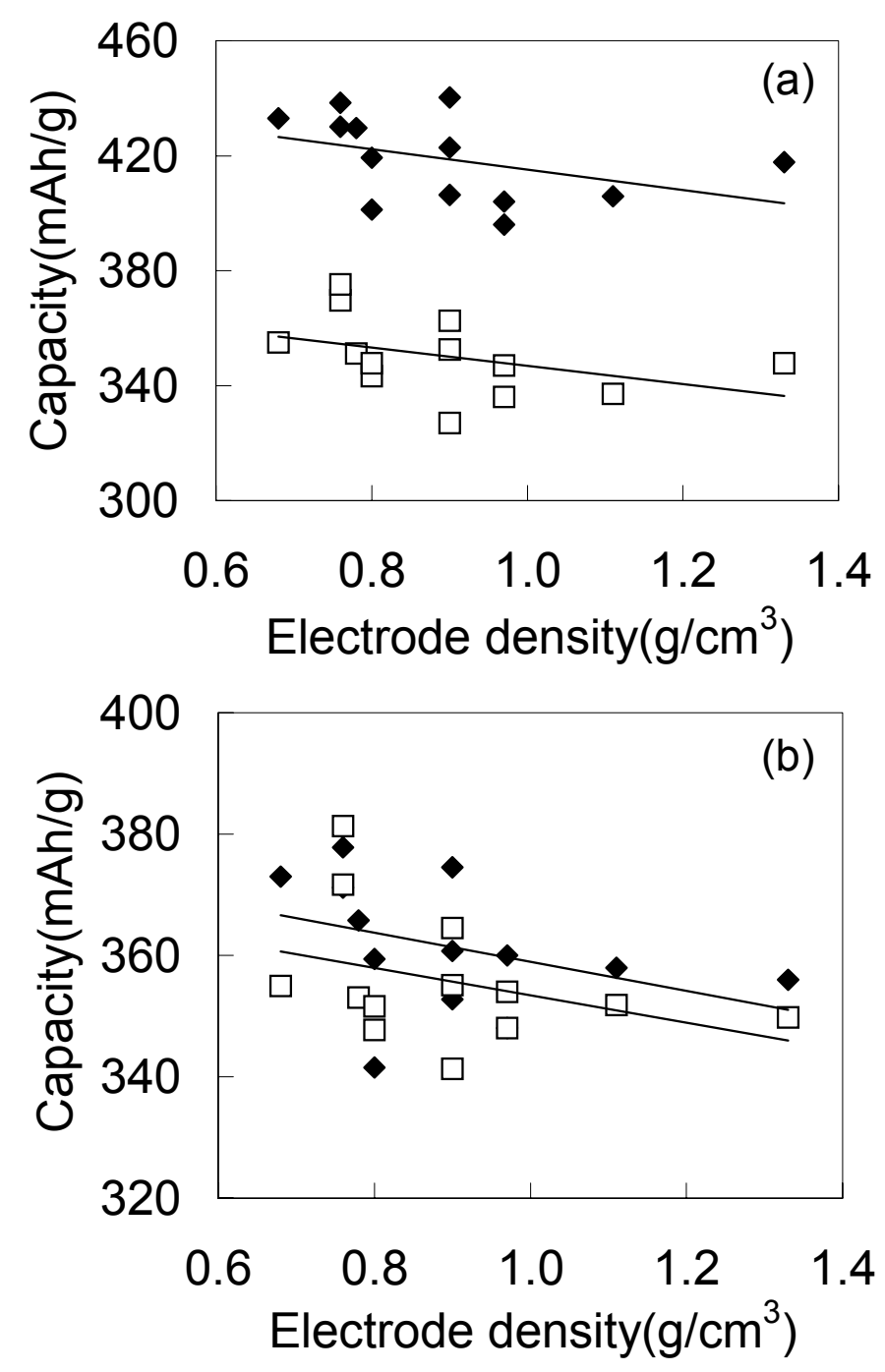

Fig. 3. 

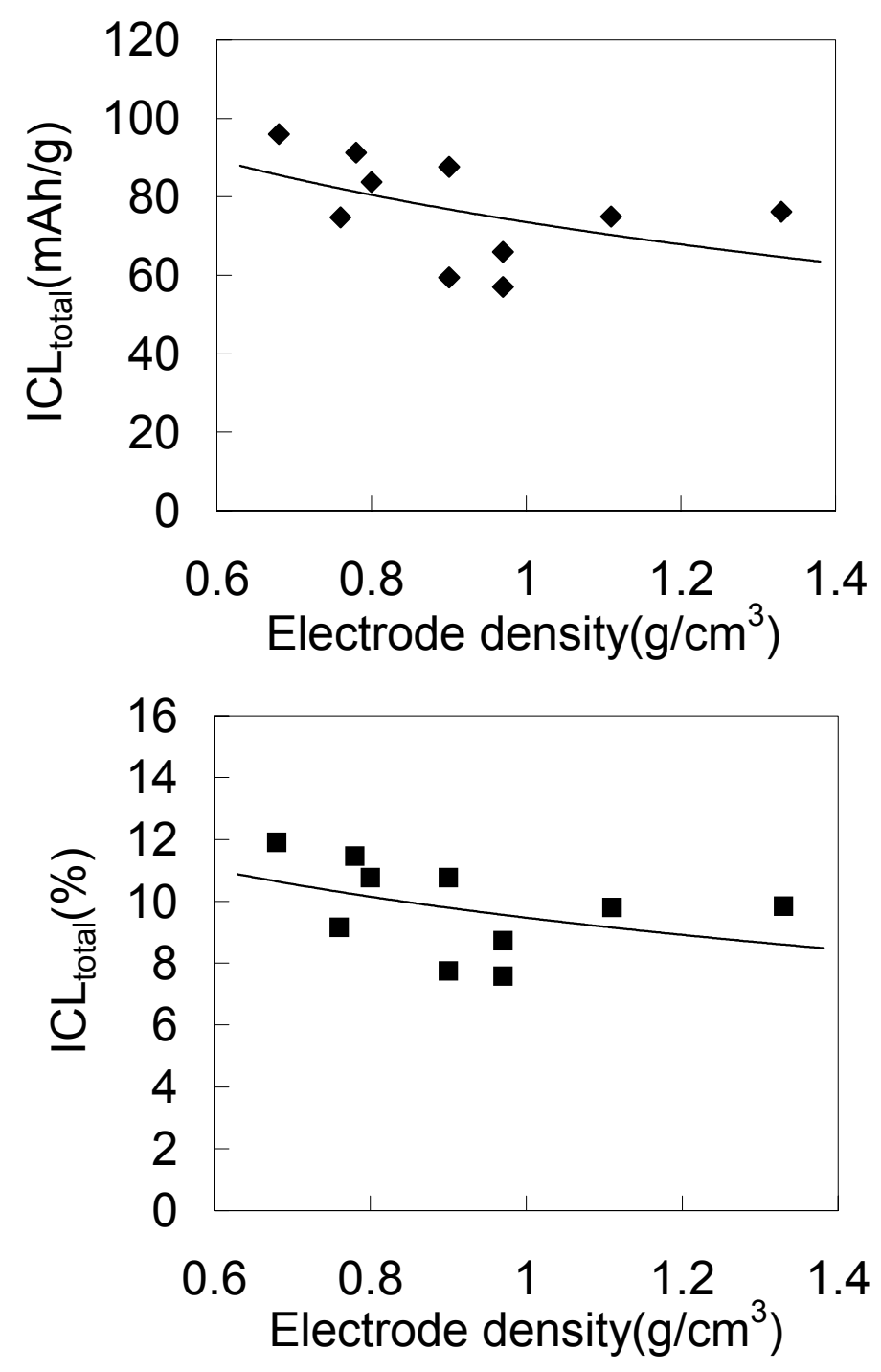

Fig. 4 


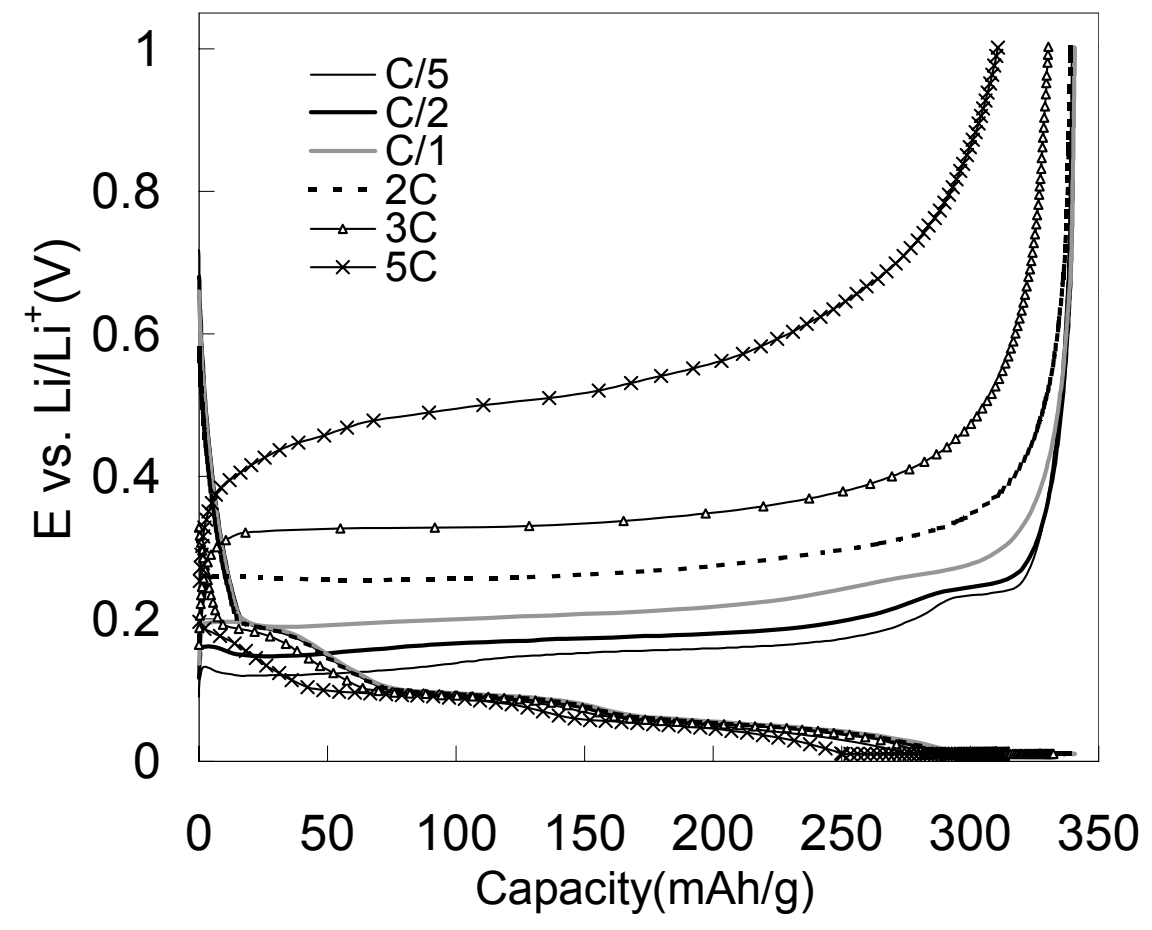

Fig. 5 


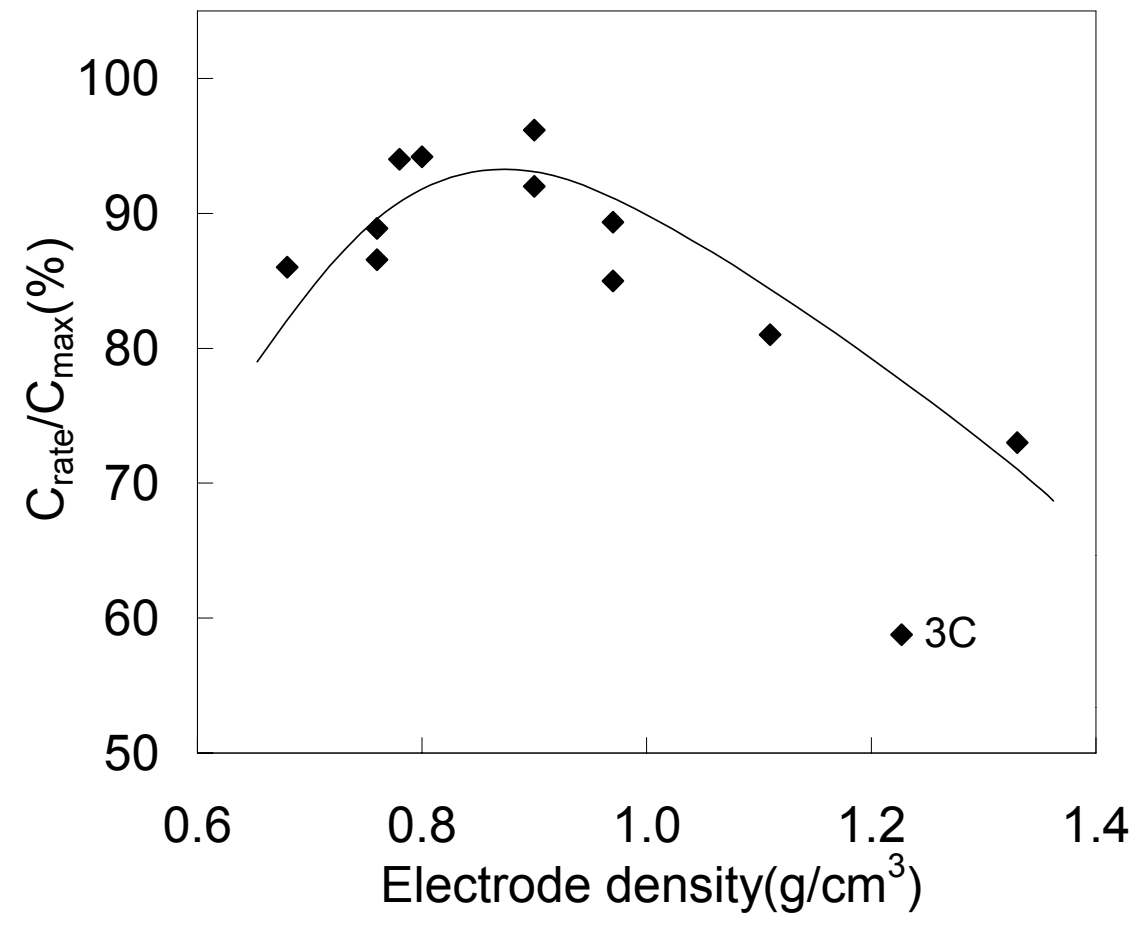

Fig. 6 


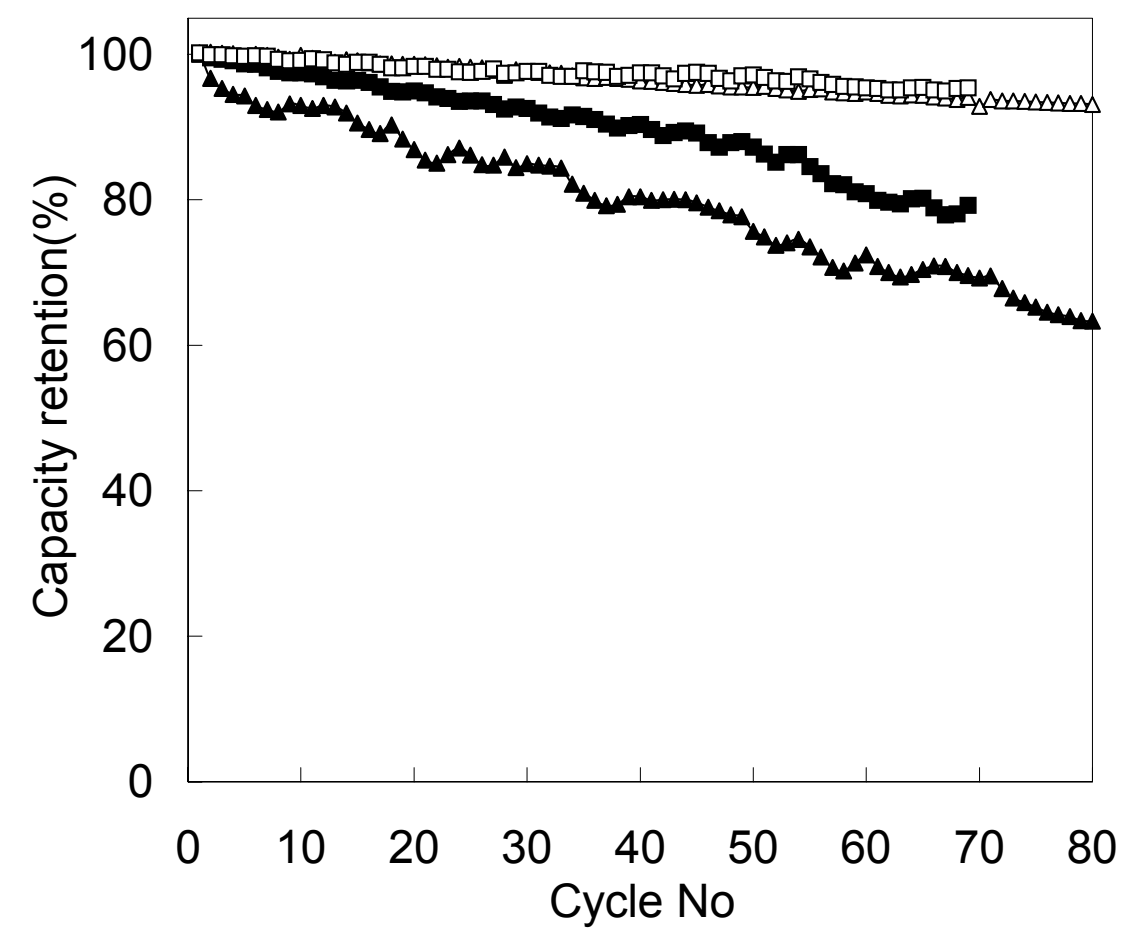

Fig. 7 